\title{
Editorial: Environmental Impact of Nanotechnology: Analyzing the Present for Building the Future
}

\author{
Renato Grillo ${ }^{1 *}$, Marcelo B. de Jesus ${ }^{2}$ and Leonardo F. Fraceto ${ }^{3 *}$ \\ ${ }^{1}$ Department of Physics and Chemistry, School of Engineering, São Paulo State University, Ilha Solteira, Brazil, ${ }^{2}$ Department \\ of Biochemistry and Tissue Biology, University of Campinas, Campinas, Brazil, ${ }^{3}$ Institute of Science and Technology of \\ Sorocaba, São Paulo State University, Sorocaba, Brazil
}

Keywords: nanotechnology, environment, environmental impacts, analytical methodology, regulation, nanotoxicology, risk assessment

\section{OPEN ACCESS}

Edited and reviewed by: Steve Suib,

University of Connecticut Mansfield, United States

*Correspondence: Renato Grillo

renato.grillo@unesp.br

Leonardo F. Fraceto

leonardo.fraceto@unesp.br

Specialty section

This article was submitted to Green and Sustainable Chemistry,

a section of the journal

Frontiers in Environmental Science

Received: 17 April 2018 Accepted: 07 May 2018

Published: 24 May 2018

Citation:

Grillo $R$, de Jesus $M B$ and Fraceto LF (2018) Editorial: Environmental Impact of Nanotechnology: Analyzing the Present for Building the Future.

Front. Environ. Sci. 6:34. doi: 10.3389/fenvs.2018.00034

\section{The Editorial on the Research Topic}

\section{Environmental Impact of Nanotechnology: Analyzing the Present for Building the Future}

Recent advances in nanotechnology have shown numerous societal benefits through the development or improvement of smart materials. Several engineered nanomaterials (ENMs) have been produced during the last years that may be found in related sectors like health, food, home, automotive, electronics, and computers (Hansen et al., 2016). The estimated output of ENMs produced was up to 270,000 metric tons/year and in this case considering only $\mathrm{SiO}_{2}, \mathrm{TiO}_{2}, \mathrm{FeO}_{\mathrm{x}}$, $\mathrm{AlO}_{\mathrm{x}}, \mathrm{ZnO}$, and $\mathrm{CeO}_{2}$ nanoparticles (Medina-Velo et al., 2017).

Hence, the volume and heterogeneity of engineered nanomaterials (ENMs) released into the environment during manufacture, use, transport, and disposal have been increasing steadily. Therefore, it becomes relevant to evaluate the potential impact of these ENMs on the environment and human health; particularly, since ENMs could interact with organisms and environmental complex matrices (e.g., natural organic colloids; Wagner et al., 2014; Grillo et al., 2015). These kinds of interactions can modify the fate and environmental behavior of the ENMs into the field as well as hinder their analytical detection (Nowack et al., 2015). In this context, recent studies have shown that many of interactions of ENMs with environment compartments (soil, water, air) are still flawed concerning the mechanistic, methodological, and toxicological aspects, turning problematic the development of regulatory policies (Giese et al., 2018). Moreover, environmental regulation coupled with toxicological factors are the major restraining factors of the global nanomaterials commercialization (Inshakova and Inshakov, 2017). Thus, this Research Topic was intended to bring the main "bottlenecks" related to the studies of nanotechnology, their impacts on the environment, and present possible directions to be followed in several areas within the field. Experts around the world contributed to systematic reviews, mini-reviews, perspectives, as well as, original research papers related to the area. 
Mendonça et al. summarized some of the current test guidelines and the understanding of ENMs toxicity to representative terrestrial species across multiple trophic levels, including E. crypticus/E. albidus, C. elegans, and rodents. They concluded that using representative species of various trophic levels in standardized tests would improve data quality, which in turn would help the development of regulatory policies.

Pérez-de-Luque described the uptake and distribution of nanomaterials in plants and pointed out some gaps regarding this process. Nanoparticle traits and plant species greatly affect the interaction mechanism. Thus, nanomaterials can enter and move through different pathways (apoplast vs. symplast), what influences their effectiveness and final fate. However, before the research findings are translated into the field, the author identified some hurdles: (i) the nanomaterials cost must be competitive with the current agricultural goods, (ii) safety must be guaranteed before the use in the field and (iii) consumers will distrust a new technology in the same way that happened with transgenic crops. Thus, the author suggested that we need to broaden our horizons and start looking for real practical approaches, filling the main gaps that hamper the translation from laboratory research into field applications.

Calderón-Jiménez et al. discussed advances in silver nanoparticles (AgNP) production and presented an overview of the commercial, societal, and environmental impacts of this emerging nanoparticle, and nanomaterials in general. Furthermore, the authors examined the challenges associated with AgNP characterization, discussed the importance of the development of nanoparticles reference materials. Finally, they explored the role of AgNP as a metrological mechanism to improve the quality and comparability of nanoparticles measurements.

Mckee et al. determined the toxic effect of AgNP on Folsomia candida as a model to demonstrate the impact of this kind of ENMs on terrestrial ecosystems. In addition, in this study, they compared the effects on different soils (RefeSol 01-A, LUFA 2.2, and OECD soil) using a range of silver concentration from 0.3 $\mu \mathrm{g}$ to $50 \mathrm{mg}$ of $\mathrm{Ag} \mathrm{kg}^{-1}$. Thus, the authors demonstrated that the presence of AgNPs in soil increase the inhibition of F. candida over the time. Another point discussed by the authors is that the range of concentration used in this study is environmentally relevant and that this can lead toxic effect on soil invertebrates.

Sousa et al. compared the post-emergence herbicidal activity of $\operatorname{Poly}(\varepsilon$-caprolactone) nanocapsules containing atrazine herbicide with a commercial formulation against Amaranthus viridis (slender amaranth) and Bidens pilosa (hairy beggarticks). Authors observed that the use of 10 -fold diluted atrazine-loaded PCL nanocapsules, compared with the commercial formulation

\section{REFERENCES}

Giese, B., Klaessig, F., Park, B., Kaegi, R., Steinfeldt, M., Wigger, H., et al. (2018). Risks, release and concentrations of engineered nanomaterial in the environment. Sci. Rep. 8:1565. doi: 10.1038/ s41598-018-19275-4 at the standard atrazine dose, resulted in the same inhibitory effect on root and shoot growth for both species. Hence, they concluded that atrazine-containing PCL nanocapsules improved the post-emergence effect of the herbicide.

In this context, the environmental impact of nanotechnology is one of the most exciting ongoing debate in the field. The same level of excitement brought with the nanotechnology achievements in different areas brought as well the concerning about the risks and challenges in dealing with this new technology. We showed here some of the advances that nanotechnology can bring to the agribusiness, and are notable the difficulties encountered in translating these potential products to the market. In addition, to build a future where nanotechnology improves the agricultural goods, increasing the efficiency of agrochemical, investigating the effects into the soil, and at the same time guaranteeing the safety of these goods is an ambitious quest, even because we still face an uphill battle to detect ENMs and derivatives in the environment. Also, standardized tests to assure safety and effectiveness of these materials in the environment and even need to decide about waste management processes control should be further studied. These are some of the challenges this field will have to deal shortly because everyday the amount of nanomaterial in the environment increases.

The studies published in this Research Topic provide a baseline level of data in support of the environmental impact of nanotechnology; besides this is only the top of the iceberg and an intensive investigation in this field is still required. We leave here some recommendations for building the better future of nanotechnology. First, waste management control requires additional research regarding the fate of different kinds of ENMs in a broad range of concentration. Second, we need to develop technologies capable of detecting nanomaterials in environmental systems and in the realistic range of concentrations that they will be present in the field. Finally, efforts should be made to the development of experimental and theoretical models to forecast the short- and long-term toxicity, contributing to regulation for the use of the nanomaterials in benefits of the society.

\section{AUTHOR CONTRIBUTIONS}

All authors listed, have made substantial, direct and intellectual contribution to the work, and approved it for publication.

\section{ACKNOWLEDGMENTS}

We would like to heartily acknowledge all the authors for the valuable sharing of their findings, knowledge, and opinions.

Grillo, R., Rosa, A. H., and Fraceto, L. F. (2015). Engineered nanoparticles and organic matter: a review of the state-of-the-art. Chemosphere 119, 608-619. doi: 10.1016/j.chemosphere.2014.07.049

Hansen, S. F., Heggelund, L. R., Besora, P. R., Mackevica, A., Boldrin, A., and Baun, A. (2016). Nanoproducts - what is actually available to European consumers? Environ. Sci. Nano 3, 169-180. doi: 10.1039/C5EN00182J 
Inshakova, E., and Inshakov, O. (2017). "World market for nanomaterials: structure and trends," International Conference on Modern Trends in Manufacturing Technologies and Equipment (Volgograd: Icmtmte 2017). 129.

Medina-Velo, I. A., Peralta-Videa, J. R., and Gardea-Torresdey, J. L. (2017). Assessing plant uptake and transport mechanisms of engineered nanomaterials from soil. Mrs Bullet. 42, 379-383. doi: 10.1557/ mrs.2017.87

Nowack, B., Baalousha, M., Bornhoft, N., Chaudhry, Q., Cornelis, G., Cotterill, J., et al. (2015). Progress towards the validation of modeled environmental concentrations of engineered nanomaterials by analytical measurements. Environ. Sci. Nano 2, 421-428. doi: 10.1039/ C5EN00100E

Wagner, S., Gondikas, A., Neubauer, E., Hofmann, T., and Von Der Kammer, F. (2014). Spot the difference: engineered and natural nanoparticles in the environment-release, behavior, and fate. Angewandte Chem. Int. Ed. 53, 12398-12419. doi: 10.1002/anie.201405050

Conflict of Interest Statement: The authors declare that the research was conducted in the absence of any commercial or financial relationships that could be construed as a potential conflict of interest.

Copyright (c) 2018 Grillo, de Jesus and Fraceto. This is an open-access article distributed under the terms of the Creative Commons Attribution License (CC $B Y)$. The use, distribution or reproduction in other forums is permitted, provided the original author(s) and the copyright owner are credited and that the original publication in this journal is cited, in accordance with accepted academic practice. No use, distribution or reproduction is permitted which does not comply with these terms. 